the development of cirrhosis, known to increase infectious risk. Surprisingly, there are no data on the safety of TNF antagonists in patients with chronic inflammatory disease and NAFLD or cirrhosis.

Objectives: To assess infectious and liver safety of the main TNF blockers used in chronic inflammatory diseases in patients with cirrhosis or NAFLD.

Methods: A systematic review of the literature, following the Prisma recommendations, was conducted on the Pubmed and Embase databases with the following keywords: "adalimumab", "infliximab", "etanercept", "certolizumab", "golimumab" "TNF -blockers "AND" liver cirrhosis "," non alcoholic fatty liver disease ". We selected only studies including patients treated with TNF blockers and with cirrhosis or ultrasonically characterised NAFLD. We excluded animal models and nonEnglish articles.

Results: We identified 39 articles and only 11 fulfilled the inclusion criteria. 9 Case Reports have reported the tolerance of TNF-blockers in patients with cirrhosis and one controlled study (44 patients) assessed the safety of etanercept in case of NAFLD. One study (7 patients) investigated the impact of infliximab in refractory autoimmune hepatitis. The cause of cirrhosis was primary biliary cholangitis ( 5 cases), alpha1 antitrypsin deficiency ( 4 cases) and post hepatitis $B$ cirrhosis ( 2 cases). All cirrhosis were compensated. Inflammatory diseases requiring the introduction of TNF blocker were rheumatoid arthritis $(n=5)$, psoriatic arthritis $(n=4)$, ulcerative colitis $(n=2)$ and psoriasis $(n=44)$. The TNF-blockers prescribed were adalimumab in 2 patients, infliximab in 11 patients and etanercept in 49 patients. The duration of treatment ranged from 6 to 24 months. For the 9 cirrhotic patients with an inflammatory disorder, no infection was reported and two of them ( 2 cases of primary biliary cholangitis) even had an improvement in liver function secondary to the introduction of biotherapy. For the 7 patients receiving infliximab to treat auto-immune hepatitis, 5 patients presented recurrent infections. For patients with NAFLD, no infectious event was reported and an improvement of the hepatic biological parameters was observed, suggesting an improvement in liver function.

Conclusions: The results of this review suggest that in case of compensated cirrhosis, TNF-blockers were not deleterious for the liver and did not increase the infectious risk. In case of auto-immune cirrhosis, TNF-blockers increased the infectious risk. In case of NAFLD, TNF-blockers might improve liver function and prevent fibrosis.

Disclosure of Interest: None declared

DOI: 10.1136/annrheumdis-2018-eular.5865

\section{AB0439 TRAVELLING WITH ARTHRITIS: A CROSS-SECTIONAL ANALYSIS OF DANISH ARTHRITIS PATIENTS TREATED WITH BIOLOGICS}

F. Szabados $^{1}$, C. Rasmussen ${ }^{1}$, A. Linauskas ${ }^{1,2}$, P. Leutscher ${ }^{3}$, J. Kragh $^{1}$. ${ }^{1}$ Department of Rheumatology, North Denmark Regional Hospital, Hjorring; ${ }^{2}$ Department of Rheumatology, Aarhus University Hospital, Aarhus; ${ }^{3}$ Centre for Clinical Research, North Denmark Regional Hospital, Hjorring, Denmark

Background: The development and introduction of biologics has rapidly revolutionised the therapeutic approach of chronic inflammatory diseases. Well-treated patients have high physical activity levels and long life expectancy. They travel widely for holiday, business or family visits. Biological drugs are administered either intravenously or subcutaneous and have to be kept cool.

Objectives: To describe the travel patterns, the extent of pre-travel advice, travel insurance, vaccinations, adherence to biological treatment, and self-reported health related problems encountered by rheumatology patients in biologic treatment during their travel.

Methods: A cross-sectional study was conducted in an out-patient clinic at the Department of Rheumatology, North Denmark Regional Hospital. During 2017 a questionnaire with focus on travel history was distributed to 300 consecutive arthritis patients treated with biologics.

Results: A total of 273 (91\%) completed the questionnaire. Median age was 67 years, and $53 \%$ were females. Overall $64 \%$ of them were receiving subcutaneous (sc) and $28 \%$ intravenous (iv) treatment, while in $8 \%$ administration route were not stated. Overall $15 \%$ of patients reported reduced travel activity after having started biologics and $21 \%$ reported that biological treatment or disease have directly influenced their decision about travelling. A total of $74 \%$ of patients have travelled outside of Denmark and $45 \%$ of these have travelled outside of Europe while treated with biologics. Pre-travel advice was sought by $26 \%$ and travel insurance was taken out by $86 \%$ of the travellers. However, $59 \%$ did not inform the insurance company about their disease or biologics. Only $6 \%$ of the travellers have experienced minor health problems which were not related to arthritis, while three patients were hospitalised. Overall $10 \%$ of patients were given additional travel vaccination. Patients, receiving sc biologics travelled significantly more than those, receiving iv treatment: $68 \%$ versus $21 \%(p<0.05)$. Overall $42 \%$ of the travellers in sc treatment group continued to take biologics during their travel, $21 \%$ had stopped the treatment before and $5 \%$ during the travel. A large proportion (72\%) of travellers, who discontinued sc treatment prior to travelling, stopped the medication due to concerns about carrying biologics in general.

Conclusions: Biological treated patients with rheumatic diseases travel frequently. Neither health-related problems nor treatments were reported to be major problems. The main problems were failure to seek pre-travel advice worry for carrying biologics and the lack of disclosure regarding biologic treatment while seeking travel insurance. Patients receiving subcutaneous biological treatment travelled significantly more often than patients treated with intravenous biologics.

\section{REFERENCES:}

[1] Dekkiche S, de Valliere S, D`Acremont V, Genton B. Travel related health risks in moderately and severally immunocompromised patients: a casecontrol study. J Travel Med 2016:23.

[2] Askling HH, Dalm VASH. The medically immunocompromised adult traveller and pre-travel counselling:status quo 2014. Travel Medicin and Infectious Disease 2014:219-18.

Disclosure of Interest: None declared

DOI: 10.1136/annrheumdis-2018-eular.4678

\section{AB0440 1 ETHNIC MINORITIES EXPERIENCE INFREQUENT BIOLOGIC SWITCH DESPITE ACTIVE RHEUMATOID ARTHRITIS DISEASE}

G. Kerr ${ }^{1}$, on behalf of EMRAC, C. Swearingen ${ }^{2}$, S. Hochberg ${ }^{1}$, J. Ude $^{1}$, Y. Yazici $^{2}$, on behalf of Ethnic Minority Rheumatoid Arthritis Consortium. ${ }^{1} \mathrm{VAMC} / \mathrm{HUH}$, Washington; ${ }^{2}$ New York University, New York, USA

Background: The expanded therapeutic modalities in rheumatoid arthritis (RA) provide options to achieve low disease activity or remission. Yet, in routine care, the frequency and choice of switching of biologic DMARD (bDMARD) amongst ethnic subsets when there is inefficacy, is unknown.

Objectives: To evaluate frequency and choice of biologic switch in ethnic RA subsets

Methods: Patients enrolled in the Ethnic Minority RA Consortium (EMRAC), with at least one followup visit were analysed. Data included clinical outcomes as assessed by RAPID3 tender/swollen joint counts; medication use (prednisone, methotrexate, other DMARD), and bDMARD (Tumour Necrosis factor inhibitors (TNFi) and non-TNFi). Minimally clinical improvement (MCI) in RAPID3 was defined as a decrease of $\geq 3.2$ points during followup. Differences between medication usage, biologic switch, and RAPID3 improvement between race and ethnicity groups while on biologics, was investigated.

Abstract AB0440 - Table 1. Demographic and clinical features of EMRAC cohort by race group

\begin{tabular}{lccccc}
\hline & White & $\begin{array}{c}\text { African- } \\
\text { American }\end{array}$ & Hispanic & Other & Total \\
\hline N & 366 & 252 & 158 & 264 & 1040 \\
Age (years) & 55.4 & $56.5(14.5)$ & 54.4 & 53.9 & 55.1 \\
& $(15.8)$ & & $(13.5)$ & $(16.3)$ & $(15.3)$ \\
Education (years) & $15.1(3.2)$ & $13.4(3.2)$ & $12.6(4.5)$ & $15.2(3.5)$ & $14.2(3.6)$ \\
Female [N(\%)] & 286 & $208(83 \%)$ & $126(80 \%)$ & 218 & 838 \\
& $(78 \%)$ & & & $(86 \%)$ & $(81 \%)$ \\
Followup (weeks) & 57.0 & $92.8(87.6)$ & 48.7 & 52.2 & 63.2 \\
& $(53.0)$ & & $(45.0)$ & $(50.5)$ & $(63.9)$ \\
RAPID3 [0-30] & $11.3(7.2)$ & $12.9(7.1)$ & $12.6(7.7)$ & $10.8(7.5)$ & $11.9(7.3)$ \\
Tender Joints [0-28] & $1.0(3.6)$ & $2.5(5.0)$ & $2.4(4.9)$ & $0.5(2.4)$ & $1.5(4.1)$ \\
Swollen Joints [0-28] & $0.5(2.0)$ & $2.0(3.8)$ & $1.7(3.9)$ & $0.3(1.8)$ & $1.0(2.9)$ \\
Prednisone Use [N(\%)] & 130 & $89(35 \%)$ & $66(42 \%)$ & $78(30 \%)$ & 363 \\
& $(36 \%)$ & & & & $(35 \%)$ \\
Methotrexate Use [N & 207 & $130(52 \%)$ & $92(58 \%)$ & 160 & 589 \\
(\%)] & $(57 \%)$ & & & $(61 \%)$ & $(57 \%)$ \\
Other DMARD Use [N & 102 & $74(29 \%)$ & $60(38 \%)$ & 101 & 337 \\
(\%)] & $(28 \%)$ & & & $(38 \%)$ & $(32 \%)$ \\
Any Biologic Use [N & 198 & $84(33 \%)$ & $56(35 \%)$ & 105 & 443 \\
(\%)] & $(54 \%)$ & & & $(40 \%)$ & $(43 \%)$ \\
TNF Use [N(\%)] & 160 & $71(28 \%)$ & $41(26 \%)$ & $90(34 \%)$ & 362 \\
& $(44 \%)$ & & & & $(35 \%)$ \\
Non-TNF Use [N(\%)] & $54(15 \%)$ & $16(6 \%)$ & $16(10 \%)$ & $25(9 \%)$ & 111 \\
& & & & & $(11 \%)$ \\
& & & &
\end{tabular}

TNF: adalimumab, certolizumab, etanercept,

golimumab, infliximab

Non-TNF: abatacept, anakinra, toclilizumab, tofacitinib,

rituximab 
Results: 1040 subjects with 3719 follow-up visits spanning an average of 63.2 weeks were analysed. African Americans and Hispanics comprised $24 \%$ and $15 \%$, respectively. Compared to Whites, African Americans and Hispanics had significantly less education ( $p<0.001$ for both), significantly less biologic use $(p<0.001$ for both) and significantly less TNF use ( $p<0.001$ for both). African Americans had significantly higher RAPID3 scores at enrollment than Whites as well $(\mathrm{p}=0.018)$.

Switching between TNFi and non-TNFi was recorded in only 9 subjects, with 7 subjects switching from TNFi to non-TNFi. There was no statistical difference between race/ethnic groups in frequency of bDMARD switching, nor within bDMARD class (TNFi class, $p=c c$; non-TNFi class, $p=b b$ ). bDMARD treatment led to $\mathrm{MCl}$ in RAPID3 in 101 (38\%) subjects and in more African Americans (29 [48\%]) and Hispanics (12 [41\%]) than in Whites (49 [37\%]) (but not statistically significant)

Conclusions: In our cohort, disparity was seen in bDMARD use between race and ethnic groups but had similar and infrequent biologic switch. Based upon these data, efforts to eliminate biologic use disparity remains paramount and supersedes concerns regarding disparity in biologic switching.

Disclosure of Interest: G. Kerr Grant/research support from: BMS, Genentech, Pfizer, C. Swearingen Grant/research support from: BMS, Genentech, Pfizer, S. Hochberg: None declared, J. Ude: None declared, Y. Yazici Grant/research support from: BMS, Genentech, Pfizer

DOI: 10.1136/annrheumdis-2018-eular.3001

\section{\begin{tabular}{|l|l}
\hline AB0441 DRUG SURVIVAL AND REASON FOR DROP-OUT IN \\
\hline
\end{tabular} RHEUMATOID ARTHRITIS PATIENTS WITH A NON MEDICAL SWITCH FROM ORIGINATOR TO BIOSIMILAR ETANERCEPT - PRELIMINARY DATA FROM A NORWEGIAN MULTICENTER STUDY}

G. Haugeberg ${ }^{1,2}$, G. Bakland ${ }^{3}$, E. Rødevand ${ }^{4}$, B.T. Fevang ${ }^{5}$, I.J.W. Hansen ${ }^{6}$, A. Diamantopoulos ${ }^{2} .{ }^{1}$ Research Unit, Hospital of Southern Norway Trust, Kristiansand.S; ${ }^{2}$ Rheumatology, MARTINA HANSENS HOSPITAL, Bærum; ${ }^{3}$ Rheumatology, UNN, Tromsø; ${ }^{4}$ Rheumatology, St. Olavs Hospital, Trondheim; ${ }^{5}$ Rheumatology, Haukeland University Hospital, Bergen; ${ }^{6}$ Rheumatology, Hospital of Southern Norway Trust, Kristiansand.S, Norway

Background: Norwegian rheumatologists are encouraged to prescribe the low est-priced biologic DMARDs according to the national tender system. Thus, nonmedical switch from the originator drug to its biosimilar is extensively performed There is a need for more real life data to clarify the clinical outcomes, dropout rates and reasons for these dropouts after a non-medical switch from the originator to biosimilar ETN.

Objectives: To explore drug survival and clinical outcomes in rheumatoid arthritis (RA) patients after a non-medical switch from the originator to biosimilar ETN (SB4) in ordinary outpatient clinics across Norway.

Methods: Herein we present preliminary data collected at one participating centre. Patients were monitored and data were collected by the use of a hospital clinical computer system GoTreatIT Rheuma. The computer system is also used for data collection for the Norwegian national arthritis registry, NorArtritt. Demographic, clinical and treatment data were retrieved (21st of January 2018) from the computer system for the time point of non-medical switch of ETN and the last follow up. Wilcoxon matched-pair signed rank test was used for comparison between the two-time points.

Results: Since April 2016191 RA patients (mean age 60.8 years, 67\% females) underwent a non-medical switch from originator to biosimilar ETN. Mean (SD) observation time for the 163 patients (85.3\%) still on biosimilar ETN was 1.23 (0.46) yrs. 28 patients (14.7\%) stopped treatment. Among them mean (SD) observation time for the 7 patients $(3.7 \%)$ in remission was $0.53(0.33) \mathrm{yrs}$, for the 10 patients $(5.2 \%)$ reporting adverse events $0.44(0.32)$ yrs and for the 11 patients $(5.8 \%)$ reporting lack or loss of efficacy $0.44(0.35)$ yrs. The adverse events reported was: 1 chest pain, 1 neuropathy, 1 Gl reaction, 1 visual impairment, 1 infection, 2 joint stiffness (1 patient went back on ETN SB4) and 3 skin reactions. For all 191 patients no significant change (median [IQR]) from baseline to last observation was seen for DAS28 (2.1 [1.5-2.8] vs 1.9 [1.5-2.5], $\mathrm{p}=0.33), \mathrm{MHAQ}$ (0.3 [0.0-0.7] vs $0.4[0.1-0.6], p=0.62)$ and patient VAS global $(20.0$ [10.0-43.0] vs 25.0 [10.0-43.3] mm, $\mathrm{p}=0.73$ ), whereas CRP improved significantly during follow up (2.0 [1.0-5.0] vs 1.0 [1.0-5.5] mg/dl, $p=0.02)$. For the subgroup of RA patients who stopped treatment because of lack of efficacy a minor non-significant impairment was observed for DAS28 (2.0 [1.4-2.5] vs 2.6 [1.2-4.0], $p=0.32)$, CRP $(0.0[0.0-6.0]$ vs $3.5[0.8-13.3] \mathrm{mg} / \mathrm{dl}, \mathrm{p}=0.66)$, MHAQ $(0.1[0.0-0.1]$ vs $0.5[0.3-$ $0.5], p=0.66)$ and patient VAS global $(20.0$ [10.0-30.0] vs 29.0 [17.0-58.5] mm, $p=0.66)$.

Conclusions: Our preliminary data indicate that for the majority of patients, a non-medical switch from originator to biosimilar ETN (SB4) was well tolerated with no impairment in disease measures. Whether the reported adverse events were associated to the switch needs to be further studied. In patients who stopped the biosimilar because of lack of effect only a minor numerically increase in disease measures was seen. Our promising preliminary results need to be confirmed in a large scale study.

Disclosure of Interest: G. Haugeberg Shareholder of: DiaGraphIT AS, G. Bak land: None declared, E. Rødevand: None declared, B. T. Fevang: None declared, I. J. Hansen: None declared, A. Diamantopoulos: None declared DOI: 10.1136/annrheumdis-2018-eular.4716

\section{AB0442 LONG-TERM SAFETY AND EFFICACY OF BIOSIMILAR INFLIXIMAB (CT-P13) AFTER SWITCHING FROM ORIGINATOR INFLIXIMAB: RESULTS FROM THE 26- WEEK OPEN LABEL EXTENSION OF A NORWEGIAN RANDOMISED TRIAL}

G.L. Goll $^{1}$, K.K. Jørgensen ${ }^{2}$, J. Sexton ${ }^{1}$, I.C. Olsen ${ }^{1}$, N. Bolstad ${ }^{3}$, M. Lorentzen ${ }^{4}$, E. A. Haavardsholm ${ }^{1}$, C. Mørk ${ }^{5}$, J. Jahnsen ${ }^{2}$, T.K. Kvien ${ }^{1}$, on behalf of The NORSWITCH study group. ${ }^{1}$ Dept of Rheumatology, Diakonhjemmet Hospital, Oslo; ${ }^{2}$ Department of Gastroenterology, Akershus University Hospital, Lørenskog; ${ }^{3}$ Dept of Medical Biochemistry, OUS-Radiumhospitalet, ${ }^{4}$ Department of Dermatology, Rikshospitalet, Oslo; ${ }^{5}$ Department of Cancer and Molecular Medicine, Norwegian University of Science and Technology, Trondheim, Norway

Background: The NOR-SWITCH study was funded by the Norwegian government to investigate if switching from originator infliximab (INX) to biosimilar CT $\mathrm{P} 13$ is safe in rheumatoid arthritis (RA), spondyloarthritis (SpA), psoriatic arthritis (PsA), Crohn's disease (CD), ulcerative colitis (UC), and chronic plaque psoriasis (Ps).

Objectives: Assessing efficacy, safety. immunogenicity at week 78 in patients on CT-P13 for 78 weeks (maintenance group) vs CT-P13 for 26 weeks (switch group).

Methods: 481 adult patients on stable originator infliximab were randomised 1:1 to continued INX or switch to CT-P13 treatment in the main study ${ }^{1}$. All extension participants received CT-P13. The primary endpoint was disease worsening, analysed with logistic regression, adjusted for diagnosis and treatment duration.

Abstract AB0442 - Table 1

\begin{tabular}{|c|c|c|c|}
\hline $\begin{array}{l}\text { Demographic and baseline } \\
\text { characteristics ( } 52 \mathrm{w} \text { ) } \\
\text { Number of patients (FAS) }\end{array}$ & $\begin{array}{l}\text { Maintenance } \\
\text { group } \\
197\end{array}$ & $\begin{array}{l}\text { Switch } \\
\text { group } \\
183\end{array}$ & $\begin{array}{l}\text { Data are } \mathrm{n}(\%) \text { or } \\
\text { mean }(\mathrm{SD})\end{array}$ \\
\hline Age (years) & $48.8(14.9)$ & $48(14.3)$ & \\
\hline $\begin{array}{l}\text { Duration of ongoing infliximab } \\
\text { treatment (years) }\end{array}$ & $7.7(3.8)$ & $7.4(3.5)$ & \\
\hline $\begin{array}{l}\text { Concomitant immunosuppressive } \\
\text { therapy }\end{array}$ & $97(49 \%)$ & $75(41 \%)$ & \\
\hline Rheumatoid arthritis & 27 (14\%) & $28(15 \%)$ & \\
\hline Spondyloarthritis & $38(19 \%)$ & $29(16 \%)$ & \\
\hline Psoriatic arthritis & $9(5 \%)$ & $11(6 \%)$ & \\
\hline Crohn's disease & $65(33 \%)$ & $62(34 \%)$ & \\
\hline Ulcerative colitis & $42(21 \%)$ & $38(21 \%)$ & \\
\hline Psoriasis & $16(8 \%)$ & $15(8 \%)$ & \\
\hline \multicolumn{4}{|l|}{ Disease characteristics } \\
\hline DAS $28 \mathrm{RA}$ & $2.4(0.9)$ & $2.8(0.9)$ & \\
\hline DAS 28 PsA & $2.1(1.1)$ & $2.9(1.8)$ & \\
\hline ASDAS (SpA) & $1.9(0.8)$ & $1.7(0.7)$ & \\
\hline Disease worsening & 190 & 173 & Risk difference \\
\hline Number of patients (PPS) & & & $(95 \% \mathrm{Cl})$ \\
\hline All & $32(16.8 \%)$ & $\begin{array}{c}20 \\
(11.6 \%)\end{array}$ & $-5.9 \%(-12.9-1.1)$ \\
\hline Rheumatoid arthritis & $9(34.6 \%)$ & $6(22.2 \%)$ & $\begin{array}{c}-10.5 \%(-34.6- \\
13.6)\end{array}$ \\
\hline Spondyloarthritis & $3(7.9 \%)$ & $2(7.1 \%)$ & $-0.6 \%(-13.5-12.2)$ \\
\hline Psoriatic arthritis & $1(12.5 \%)$ & $3(33.3 \%)$ & $20.8 \%(-17.6-59.1)$ \\
\hline
\end{tabular}

ASDAS, Ankylosing Spondylitis Disease Activity Score. DAS28, Disease Activity Score in 28 joints.

Results: 380 patients entered the extension trial. Demographic and baseline (52 w) characteristics of the extension study population are shown (table 1). Dis ease worsening in the study arms (Per Protocol Set, PPS) and in each diagnosis (explorative analyses) are shown (table 1). Generic disease variables, disease specific composite measures, trough drug levels, anti-drug antibodies and reported adverse events were comparable between groups (data not shown).

Conclusions: We found no difference between patients switched from INX to CT-P13 vs those on maintained CT-P13

\section{REFERENCE:}

[1] Jørgensen KK, Olsen IC, Goll GL, et al. Switching from originator infliximab to biosimilar CT-P13 compared to maintained treatment with originato infliximab (NOR-SWITCH): A 52-week randomised double-blind non-inferiority trial. Lancet 2017 Jun 10;389(10086):2304-2316. 